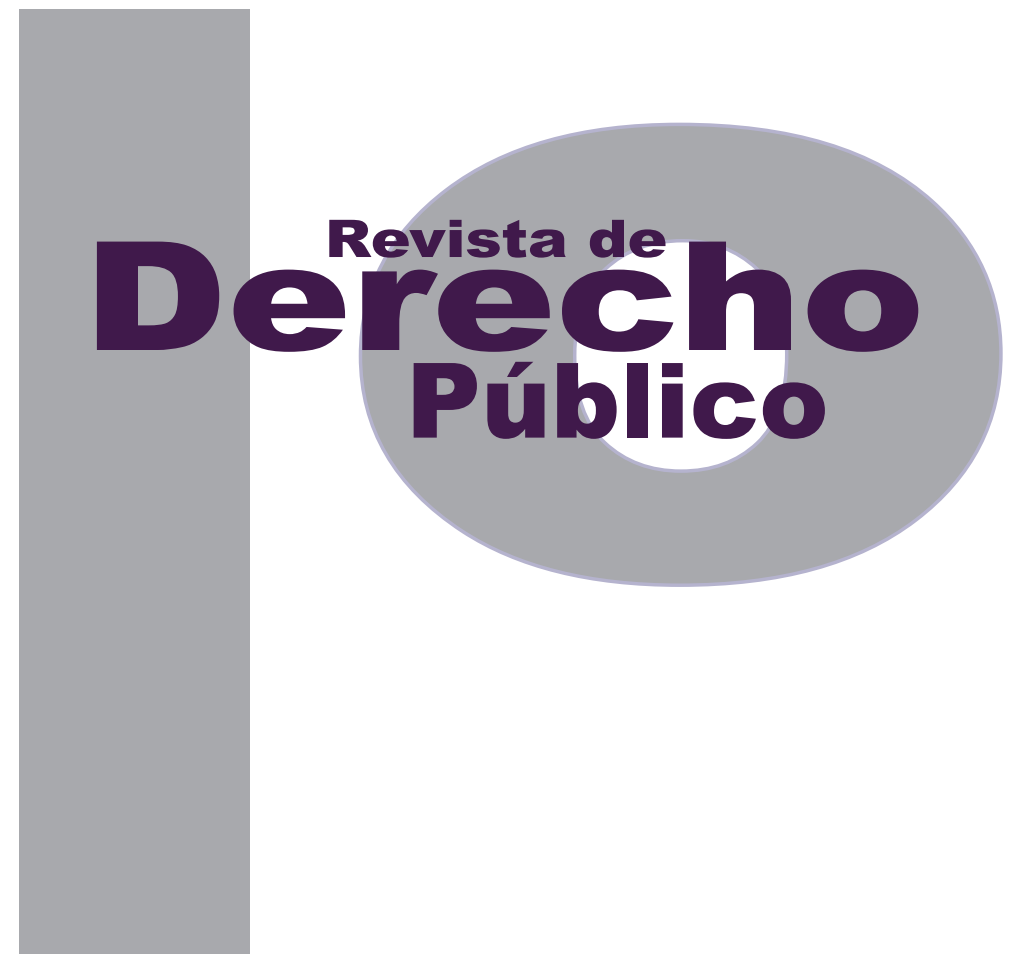

\title{
LA PIRATERÍA MARÍTIMA Y LOS VACíOS LEGALES PARA COMBATIRLA
}

\author{
MARLON IVÁN MALdonAdo NARVÁEZ \\ Artículo de reflexión \\ DOI: http://dx.doi.org/10.15425/redepub.34.2015.10
}

Universidad de los Andes

Facultad de Derecho

Revista de Derecho Público N. ${ }^{\circ} 34$

Enero - Junio de 2015. ISSN 1909-7778 


\section{La piratería marítima y los vacíos legales para combatirla}

\section{Resumen}

La presente investigación está centrada en el aumento de la piratería marítima durante los últimos años, y las razones por las cuales los diferentes intentos de muchos Estados para lograr una solución a este delito, que tantas pérdidas genera, han sido insuficientes. Inicia con una breve introducción al tema, y posteriormente se profundiza en una de las razones que entendemos puede ser la responsable de este problema: la definición de piratería. Se realiza un examen minucioso del documento internacional más importante sobre este particular, desde las diferentes situaciones que podrían encuadrarse o no dentro del problema. Lo anterior permite evidenciar la necesidad de unidad de criterios al respecto y la suscripción de un nuevo documento internacional sobre piratería, para lograr un combate más efectivo de este delito.

Palabras clave: piratería marítima, definición de piratería, acuerdo internacional, alcances nacionales, control de la piratería.

\section{Maritime piracy and the legal gaps to combat it}

\section{Abstract}

This research focuses on increasing maritime piracy in recent years and the reasons why the various attempts by many states to achieve a solution to this crime that generates many losses have been insufficient. So is a brief introduction to the subject, and then deepen into one of the reasons that we understand may be responsible for this problem: the definition of piracy. A thorough examination of the most important international document on the subject is made from the different situations that could fit or not within it. This allows to see how today is required to unify criteria about to generate a new international document on piracy for a more effective fight against this crime.

Keywords: maritime piracy, piracy's definition, international agreement, national scope, piracy's control.

\section{A pirataria marítima e os vazios legais para combatê-la}

\section{Resumo}

A presente pesquisa está centrada no aumento da pirataria marítima durante os últimos anos, e as razões pelas quais as diferentes tentativas de muitos Estados para conseguir uma solução a este delito, que tantas perdas gera, têm sido insuficientes. Inicia com uma breve introdução ao tema, e posteriormente se aprofunda em uma das razões que entendemos que pode ser a responsável deste problema: a definição de pirataria. Realiza-se um exame minucioso do documento internacional mais importante sobre este particular, desde as diferentes situações que poderiam enquadrar-se ou não dentro do problema. 0 anterior permite evidenciar a necessidade de unidade de critérios a respeito e a subscrição de um novo documento internacional sobre pirataria, para conseguir um combate mais efetivo deste delito.

Palavras-chave: pirataria marítima, definição de pirataria, acordo internacional, alcances nacionais, controle da pirataria. 


\title{
La piratería marítima y los vacíos legales para combatirla*
}

\author{
Marlon Iván Maldonado Narváez ${ }^{* *}$
}

\section{SUMARIO}

Introducción - I. DESARROLLO HISTÓRICO-JURÍDICO DE LA PIRATERÍA - II PROBLEMAS RELATIVOS A LA DEFINICIÓN DE PIRATERÍA - A. Definición de piratería de la CNUMAR - 1 Limitación a los actos ocurridos en alta mar - 2. Necesidad de un segundo buque - 3. La existencia de un fin privado - 4. Otras críticas - III CONCLUSIONES - Referencias.

Cómo citar este artículo: Maldonado Narváez, M. I. (Junio, 2015). La piratería marítima y los vacíos legales para combatirla. Revista de Derecho Público, 34. Universidad de los Andes (Colombia).

** Abogado Corporación Universitaria de la Costa, máster en Derecho Empresarial Universidad Autónoma de Barcelona, docente de Derecho Internacional y Propiedad Intelectual Universidad de Boyacá, Colombia. Correo electrónico: mmaldonadon@hotmail.com 
Introducción

La piratería constituye una de las más grandes amenazas al intercambio marítimo mundial. En la actualidad existen reportes de que en casi todos los mares del mundo se están registrando ataques piratas. Por lo tanto la piratería ha dejado de ser una historia romántica, para convertirse en una constante preocupación.

De acuerdo con las estadísticas de la Organización Marítima Internacional (омı), entre los años 1984 a 2013 se presentaron o se intentaron al menos 6752 casos; $^{1}$ datos que se considera no reflejan el volumen verdadero, ya que algunos capitanes de barco prefieren no reportarlos para evitar los aumentos en las primas de seguro, además de los costes que puede tener mantener una embarcación en puerto mientras se realiza la investigación (Eadie, 2004), situación que como indica Kraska (2009) ha llevado a infra asegurar el real valor de las mercancías transportadas. Ante este escenario de falta de información absoluta de lo que realmente ocurre es difícil mejorar los resultados para frenarlo (Bichou, 2008).

Pese a que en la actualidad se están realizando grandes esfuerzos, sus frutos son limitados ya que se ha logrado controlar la situación en algunas zonas, pero en otras se ha incrementado. Este contexto, aunque se encuentra focalizado

1 Las notificaciones se iniciaron en 1984 con ocasión de la Resolución A.683 (17) de "Prevención y represión de los actos de piratería y robos a mano armada perpetrados contra los buques". Véase el informe anual 2013 sobre reportes de piratería y robo armado de la omı, disponible en http://www.imo.org/OurWork/Security/SecDocs/Documents/ PiracyReports/208_Annual_2013.pdf, consultado el 30/08/2014. en algunas zonas geográficas, afecta a todo el mundo por igual. Así, el consumidor final de cualquier producto importado proveniente de estas regiones, o que deba navegar por cualquiera de estas zonas, tendrá que soportar los sobrecostos que ello genera.

En el presente los piratas se encuentran fuertemente armados, puesto que cambian garfios, espadas y machetes por armas de fuego, pistolas automáticas, fusiles y lanza granadas (Ndumbe y Moki, 2009). Los reportes registran, además, que actualmente los piratas han causado lesiones y heridas, e incluso asesinado a gran cantidad de tripulantes y pasajeros, por lo cual muchas víctimas prefieren no volver al mar (Chalk, 2008); además están optando por el secuestro de los tripulantes a cambio del pago de rescates. Escenario este que ha generado un ambiente de pesimismo sobre las posibilidades reales de poner fin a dicho problema (Sakhuja, 2000).

Este resurgimiento de la piratería ha sido atribuido a una mezcla de varios factores: primero, las dificultades económicas que padecen los Estados ubicados en estas zonas; segundo, el incremento de barcos que circulan por los océanos motivados por el alto volumen de intercambio comercial y al volcamiento del mundo moderno al mar en búsqueda de recursos económicos y alimenticios; tercero, la terminación de la guerra fría, que según la doctrina ha presentado una disminución de las fuerzas navales que anteriormente patrullaban. Lo anterior, sin descontar la facilidad con la que hoy en día los piratas logran conseguir armamento (Forsyth, Gisclair y 
Forsyth, 2009), y que el problema se concentra especialmente en zonas de alto tráfico marítimo (Kraska, 2009).

La piratería marítima es un problema con muchos matices, razón por la cual varios de los esfuerzos realizados para terminarla han sido infructuosos. Históricamente se ha logrado controlarla, pero nunca resolver el problema de raíz. Warner (2010) considera que la mejor manera de afrontarla es por tierra, viéndola como un tema de simple voluntad política, relacionada con la realización de acciones que permitan mejorar la calidad de vida de las personas que optan por lanzarse al mar a cometer este delito.

De acuerdo con lo anterior, se entiende que la mejor manera de combatir un problema internacional es con un acuerdo unánime. No es fácil luchar con un delito que tiene tantas facetas. Por lo tanto, en este trabajo se mostrará cómo la falta de un acuerdo sobre lo que es la piratería marítima está dificultando los actos que se realizan para combatirla.

Todos estos esfuerzos pretenden identificar exactamente de qué se trata la piratería; encontrar la diferencia entre la piratería y el terrorismo servirá igualmente para evitar especulaciones al respecto. Así también en sectores como el asegurador, se podrán realizar de manera más concreta y correcta las evaluaciones del riesgo.

\section{DESARROLLO HISTÓRICO-JURÍDICO DE LA PIRATERÍA}

En tiempos bastante lejanos los griegos y los romanos veían la piratería como una actividad legal e inclusive honrosa para quien la ejercía, siempre que su objeto fuera despojar de sus propiedades a toda nave extranjera, y contribuyera a su vez a aprovisionar de recursos al propio imperio al que servían, ataques que podían incluir la toma de ciudades costeras (Carvajal, 2007, pp. 233, 237 y 243). La piratería podía considerarse entonces una forma de vida completamente legal, que servía además como protección para el propio comercio frente a los piratas provenientes de otras regiones (Carvajal, 2007, p. 242), práctica que de acuerdo con Jesús (2003) fue realizada incluso por familias ilustres de la época. No obstante lo anterior, según Birnie (1987), es posible encontrar en el Digesto de Justiniano referencias legales, que se realizaron hacia el año 529 a. C., en las que se reprochaba la comisión de este delito.

Su estudio llegó a estimarse innecesario; así por ejemplo, McDougal y Burke (1987) en su obra Public Order of the Oceans, anotaban que por no considerarse a la piratería como una amenaza, no era de importancia realizar un estudio profundo sobre "los laberintos legales" que la caracterizaban. Birnie (1987) apunta que llegó a pensar que las leyes para prevenirla podían ser utilizadas para otro tipo de situaciones más puntuales como el contrabando de licor.

Sin embargo, solo fue a partir del siglo XV, debido al incremento de la navegación a través 
de nuevas rutas comerciales, que la piratería se convirtió en una amenaza mayor para el comercio en general, considerándose la "época de oro” de este delito (Rodríguez, 1997). A partir de ese momento histórico es posible entender el aumento del número de normas que regulan el tema.

En el año 1536, Enrique VIII de Inglaterra promulgó la ley contra agravios de mar, ${ }^{2}$ la cual marcó un punto de partida en lo que podría considerarse la moderna regulación de dicho delito, y sirvió como fundamento para la posterior promulgación de The English Act Of Piracy de 1698, norma esta que puede constituir la primera ley moderna sobre el tema (Zou, 2009). Esta nueva ley, mejor desarrollada, propendía por una más eficaz supresión de la piratería, y además de la pena impuesta permitía incluso la expropiación de los bienes robados (Morrison, 1932). Varios años después, en las Ordenanzas de la Armada Real Española de mayo de 1748, entre otros temas, se declaró que a los piratas debía considerárseles enemigos de la raza humana, sentencia esta que Johnson y Pladdet (2003) anotan que ya había sido propuesta por Hugo Grocio en 1609.

La opinión que se había generado en torno a la piratería permite entender por qué en la mayoría de estas primeras regulaciones, que se desarrollaron para poner freno a dicha conducta, se castigó con penas bastante severas, incluyendo la pena de muerte como una forma de intimidar

2 Conocida como The offences at sea act respecto de las consecuencias de la comisión de dicho delito (Corrales, 2004).

En la mayoría de los casos, los Estados individualmente desarrollaron sus propias normas sobre piratería, adaptándolas a sus necesidades particulares e introduciendo variedad de definiciones de esta (McDougal y Burke, 1987). Se puede destacar, por ejemplo, el caso de los Estados Unidos, que en la sección 8 de su Constitución política de 1789 autorizó al Congreso para que promulgara una ley sobre piratería, la cual fue publicada en 1790. Esta norma, al igual que otras leyes desarrolladas en Francia y Alemania, tomaron en cuenta los avances de Inglaterra sobre la materia, adaptándolos a su propia normativa.

Como se ha observado, inicialmente la piratería fue regulada solo de manera individual por los distintos Estados, mas con el crecimiento del interés por la navegación, a partir de la expansión del principio de libertad de los mares, ${ }^{3}$ y de la necesidad de mantener la seguridad de los navegantes en altamar, se empezaron a desarrollar acuerdos entre Estados para garantizar la navegabilidad, y la disminución de la amenaza de este delito.

Así, por el Tratado de París de 16 de abril de 1856, ${ }^{4}$ Inglaterra, Francia y Rusia se compro-

3 Principio mare liberum de Hugo Grocio, publicado en el año 1609, el cual inicialmente sirvió para justificar la navegación holandesa por las aguas del nuevo mundo. Sin embargo la importancia de este principio ha sido tal que sin él no se podría concebir la navegación en los términos que actualmente la conocemos.

4 Tratado sobre la abolición del corso; España se adhirió a este tratado en septiembre de 1907, y su publicación se dio el 20 de enero de 1908. 
metían a no usar piratas contra embarcaciones con banderas de cualquier otro Estado firmante del tratado. Los corsarios, que eran las personas contratadas por los diferentes Estados, solo serían objeto de dicho tratado en la medida en que se apartaran de este (Rodríguez, 1997).

Por su parte la Convención de Montevideo de 1887, que propendía por la unificación de las legislaciones de los Estados americanos, establecía que la lucha contra la piratería debía realizarse conjuntamente entre los Estados americanos, como una forma de contrarrestar la amenaza de los piratas provenientes de Europa.

Estos dos tratados constituyen los primeros instrumentos internacionales relacionados con la lucha frontal contra este delito. Sin embargo, la regulación internacional sobre el tema se estancó por la disminución que se dio producto de las tensiones que las dos guerras mundiales produjeron en la navegación marítima más que por los buenos resultados que hubiesen podido arrojar dichas convenciones internacionales.

Más recientemente, la Convención de Ginebra de 29 de abril de 1958 sobre Alta Mar, entre los artículos 14 a 22 desarrolla el concepto de piratería y las acciones que deben tomarse para suprimirla. ${ }^{5}$ Pese a ello, teniendo en cuenta el momento histórico en que se dio dicha convención, es posible concluir que la piratería ya no

5 Además de la Convención sobre Alta Mar, en esta conferencia se firmaron otros convenios relativos al mar territorial y la zona contigua: Convención de la pesca y los recursos vivos de la alta mar, Convención sobre la plataforma continental y el Protocolo facultativo sobre la jurisdicción obligatoria en la solución de controversias. constituía la preocupación que anteriormente significó, máxime en la época de postguerra y de inicios de la guerra fría (Treves, 2009).

Por último, la Convención de las Naciones Unidas sobre el Derecho del Mar (en adelante CNUMAR), firmada en Montego Bay el 10 de diciembre 1982, la cual tuvo la difícil tarea de establecer un orden jurídico aplicable a los mares y océanos, copia en sus artículos 100 al 107 los artículos de la Convención de Ginebra relativos a la piratería.

La CNUMAR hace hincapié en que la lucha frontal contra la piratería corresponde a todos los Estados, inclusive a Estados sin litoral como Suiza que también ha tomado parte en las acciones que se adelantan para poner freno a dicha situación (Kraska, 2009), sin contar con la colaboración que muchas organizaciones privadas también prestan (Sakhuja, 2000).

Este postulado refuerza el cambio en la forma como históricamente se había tratado el problema, teniendo en cuenta los intereses en juego especialmente en el tema de la navegación mercantil, y que no pueden ser circunscritos a un solo Estado. Una nave puede ser de propiedad de un nacional de un primer Estado, tener bandera de un segundo Estado, estar tripulada por personal de un tercer Estado y transportar mercancía de alguien de un cuarto Estado que habrá de entregarse en un quinto Estado (Eadie, 2004); y otros Estados también se afectan, dado que tendrán que pagar más por los productos encarecidos por el aumento en las primas de seguro, o por el incremento en los costes de los 
fletes y del transporte en general, ocasionado por el cambio de rutas a otras más seguras.

El Consejo de Seguridad de las Naciones Unidas también ha realizado pronunciamientos al respecto, siendo quizás los más importantes la S/RES/1816 del 2 de junio de 2008 y la S/ RES/1851 de 16 de diciembre de 2008, en las cuales se insta a los Estados interesados a combatir la piratería y el robo a mano armada en las costas de Somalia. ${ }^{6}$ Dichas resoluciones autorizan a los Estados a utilizar sus buques y aeronaves militares en el mar frente a la costa somalí y dan al traste con la decisión que se adoptó en el seno de la Unión Europea de iniciar una operación militar, Operación Atalanta, cuyo objetivo principal fue contribuir a la represión de los actos de piratería y el robo a mano armada frente a las costas de Somalia, así como a lograr el éxito del programa de ayuda alimentaria a las poblaciones desplazadas. $^{7}$

Además de los pronunciamientos anteriormente enunciados, existen otros intentos tendentes a regular el tema, que han sido desarrollados por otro tipo de entidades no gubernamentales aunque con reconocimiento mundial, entre las que se pueden enunciar varias directivas adoptadas por la Organización Marítima Internacional o el International Maritime Bureau.

6 Pueden verse además las resoluciones del Consejo de Seguridad n. ${ }^{\circ}$ 1814, 1816 y 1846 de 2008 sobre la situación en Somalia; la Resolución de la Asamblea General A/RES/53/32 de 6 de enero de 1999 sobre los océanos y el derecho del mar.

7 Acción Común 2008/851/PESC del Consejo de 10 de noviembre de 2008 y Decisión 2008/918/PESC del Consejo, de 8 de diciembre de 2008, sobre la Operación Militar de la Unión Europea destinada a contribuir a la disuasión, prevención y represión de la piratería y el robo a mano armada frente a las costas de Somalia.

\section{PROBLEMAS RELATIVOS A LA DEFINICIÓN DE PIRATERÍA ${ }^{8}$}

El término "pirata" proviene del griego peirate, bajo el que se subsumía un abanico de actividades ilegales que se realizaban en la antigua Grecia, así como en las costas mediterráneas. Posteriormente fueron los romanos quienes avanzaron en el tema y dieron al pirata la condición de enemigos de la humanidad (Risso, 2001, pp. 293-319 y 297). Estas primeras nociones del término son la base del desarrollo moderno del concepto de piratería.

Como se ha apreciado, a lo largo de la historia existieron normas que se preocuparon por definir y regular el delito de la piratería, aunque solo fue hasta la Convención de Ginebra de 1958 que se logró este objetivo de consolidar una definición con un gran alcance internacional. Sin embargo, el estudio de esta norma y de otros intentos de definición anteriores ha permitido observar que con el paso del tiempo, en el delito de piratería se han venido incluyendo nuevas situaciones y elementos de juicio que obligan su estudio, tema este que ya desde el año de 1935 había sido propuesto por Fairman (1935). Esto evidencia que la piratería ha venido evolucionado de manera permanente, incluyendo nuevas formas de violencia (Sobrino, 2009). Se ha convertido en una amenaza cada vez más compleja, y por tanto ha aumentado la dificultad para

\footnotetext{
8 Actualmente el término piratería también se utiliza de forma coloquial y generalizada para referirse al delito de robo de los derechos de propiedad intelectual.
} 
atacarla con las normas internacionales actuales (Sanderson, 2004, pp. 49-61).

En este sentido es importante una definición clara de piratería, que la distinga de otros delitos como el terrorismo, y del tratamiento que merece. ${ }^{9}$ Una definición que permita distinguir con claridad qué situaciones pueden enmarcarse bajo el título de piratería, robo armado u otros, evitando que ciertos actos que no constituyen piratería propiamente dicha puedan deslizarse a través de ella (Forsyth, Gisclair y Forsyth, 2009).

Lo anterior genera la necesidad de valorar los componentes que agudizan esta dificultad, e incluso categorizar los distintos delitos que podrían considerarse como piratería, entre los que cabrían la corrupción, robo en el mal, piratería y terrorismo marítimo (Dillon, 2005), con el objetivo de lograr el éxito de cualquier actuación. Lo anterior sin desconocer que es preciso tomar medidas en altamar, acompañadas de acciones en tierra que faciliten su ejecución, y dicho sea de paso desestimulen la comisión del delito, fortaleciendo las democracias en los Estados más propensos a su comisión, así como en sus Estados vecinos (Ndumbe y Moki, 2009).

Por lo tanto, cualquier definición sobre piratería, ya sea como un único delito o como una conducta compuesta, debe tratar de incluir todos estos aspectos, lo cual favorecería el desarrollo de un marco legal único (Warner, 2010). Sobre este aspecto, Kahn (1996) en su trabajo pudo

9 Véase Infra la diferencia entre el fin público y privado de la piratería. observar que existen por lo menos cinco definiciones distintas de piratería, por lo cual es preciso verificar qué delitos podrían realmente encajar como tal, ya que en algunos casos se ha utilizado la palabra para situaciones que no tienen que ver con ella (Kontorovich, 2004). Este aspecto es especialmente sentido en el ámbito de los seguros marítimos, en el cual las aseguradoras no suelen acoger ninguna de las definiciones existentes (Passman, 2009).

Un tribunal de Estados Unidos, en el caso USA vs. Smith del año 1820, definió piratería como: "robo o depredación por la fuerza sobre el mar". ${ }^{10}$ Esta definición fue dada en un momento en que los casos de piratería eran bastante numerosos, y se requería de acciones concretas, lo cual en cierto modo pudo haber llevado a imprecisiones (White, 1989). No obstante, más allá de su importancia histórica, y del apego que autores como Kontorovich (2004) pudiesen mostrar al considerar que debe dársele el mismo trato como si fuera un robo en tierra, la encontramos poco práctica.

Muchos Estados en el ejercicio de sus derechos han desarrollado sus propias normas sobre piratería, pero estas no tienen alcance internacional. Igual han hecho algunas organizaciones internacionales que buscan precisar aspectos oscuros que podrían encuadrarse dentro del concepto de piratería (McDougal y Burke, p. 808), las cuales son aplicables en la medida que se

10 "Robbery or forcible depredation upon the sea". En la misma sentencia se refieren a la piratería como "felonías en alta mar (felonies on the high seas)". Véase el caso USA vs. Smith, 18 U.S 153, 161 (1820), citado en el caso USA vs. LEI SHI, de abril 24 de 2008, n. ${ }^{\circ} 06-10389$. 
encuentren dentro del marco de tratados regionales para mitigar los efectos de este delito.

Estamos de acuerdo con Bantekas (2005) al entender que, si bien en primera instancia existe una aparente uniformidad en cuanto a las normas que regulan el tema también hay anarquía en el fondo, dada la brecha que se presenta en materia de persecución internacional cuando el delito pasa del escenario de altamar al mar territorial, como en los casos de ciertos delitos que pueden ser conocidos por cortes internacionales, a los cuales también les son aplicables las normativas nacionales de los diferentes Estados.

El sector marítimo, que por su distanciamiento en altamar ha sido por naturaleza autónomo, no precisa para poner control a este aparente desorden acudir a actos de tipo hegemónico que irían en contra de su carácter anárquico (Murphy, 2007), sino al consenso de todos los Estados para obtener un resultado efectivo de cara a las necesidades que se presentan, lo cual no debe suponer una extensión ni una limitación a la soberanía de los Estados (Urbina, 2009).

No se trata de limitar la capacidad normativa de los Estados en el sentido de desarrollar sus propias leyes al respecto. La meta debe ser que estas vayan en consonancia con las políticas internacionales; por lo tanto, lo importante sería la complementación de la norma internacional y nacional, razón por la cual no estamos de acuerdo con Cervera Pery (1992), quien considera que la normativa internacional no puede confundirse con la normativa doméstica, ya que este tipo de posturas facilitan la comisión del delito.
Un ejemplo de estas normas estatales se puede encontrar en España, en donde en virtud del artículo 96 de su Constitución Política, de la ratificación de la CNUMAR y del principio de jurisdicción universal, es competente para juzgar los casos de piratería. No obstante, dentro de la legislación penal hasta el año 2012 no existía un tipo específico que permitiera calificar los actos de piratería. ${ }^{11}$

Corrales (2004) comenta que si bien no existen tipos específicos se apela a la calificación por vía genérica, para lograr el encuadre de las conductas como piratería. Sobrino (2009) considera que dicha discrecionalidad en cabeza del juez puede ser generadora de problemas, postura apoyada por Martínez (2009) quien apunta que tal encuadre propuesto por Corrales (2004) además iría en contra del principio de legalidad, con lo cual no sería realmente posible su enjuiciamiento.

Tal modificación se realizó en virtud de la Ley Orgánica n. 5 de 2010,12 de acuerdo con la cual se introduciría un artículo 616 ter y quáter. El artículo 616 ter, quedó de la siguiente manera:

El que con violencia, intimidación o engaño, se apodere, dañe o destruya una aeronave, buque u otro tipo de embarcación o plataforma en el mar, o bien atente contra las personas, cargamento o bienes que se hallaren a bordo de las

11 Anteriormente, en la Ley Penal y Disciplinaria de la Marina Mercante, de 22 de diciembre de 1955, artículos 9 a 12, se podía encontrar una definición de piratería; esta ley fue derogada por la disposición derogatoria única, i), de la Ley 27/1992, de 24 noviembre, de Puertos del Estado y la Marina Mercante.

12 Anteproyecto de Ley de Reforma del Código penal, de 14 de noviembre de 2008. 
mismas, será castigado como reo del delito de piratería con la pena de prisión de diez a quince años.

En todo caso, la pena prevista en este artículo se impondrá sin perjuicio de las que correspondan por los delitos cometidos.

En la exposición de motivos de la norma que introdujo la reforma al Código Penal español, se observa que hace referencia a la Convención de Montego Bay de 1982 como fundamento para su promulgación, sin embargo, al verificar el contenido del citado artículo, se encuentra que no recoge los mismos elementos contenidos en la definición de dicha convención internacional.

Otro ejemplo de la falta de unidad de criterio sobre el tema se aprecia en el hecho de que siendo la CNUMAR el convenio más importante sobre la materia, actualmente Estados Unidos no lo ha firmado, siguiendo al respecto sus propias regulaciones, las cuales dada su gran influencia económica y militar son observadas por otros Estados (Urbina, 2009).

Estos dos ejemplos revelan que existe más bien una situación de heterogeneidad, lo cual facilita la comisión del delito y que se presenten casos de especulación, como por ejemplo en el sector asegurador, o de entidades que en la actualidad se dedican a la negociación con los piratas, en lo referente a la liberación de las embarcaciones y de las tripulaciones.

Los esfuerzos realizados no han sido suficientes para unificar el concepto de piratería, o encontrar uno que pueda encerrar la variedad de situaciones y escenarios en que este delito se puede desarrollar, conllevando la creación de distintas definiciones que se adaptan a cada caso en particular. Passman (2009) anota que esta ausencia de una definición única ha llevado a darle diferentes significados a la piratería de acuerdo con el ámbito del que se trate, ya sea la industria aseguradora, la industria marítima, la ley internacional o la ley criminal, por esta razón puede decirse que los postulados actuales, así como los pasados, siempre han estado marcados por un elemento de ambigüedad (Murphy, 2007).

En un informe del Comité de Transporte de la Cámara de los Comunes del Parlamento Inglés sobre la piratería (2005-2006, p. 10), expresan su preocupación sobre el tema y se adhieren a la necesidad de unificar el concepto de este delito para poder abordar el problema con éxito. Como ya se ha visto, la necesidad de una reforma es notoria, llegando incluso a decirse que ni tomando los elementos de las definiciones sobre piratería más importantes en la actualidad sería suficiente para albergar todos los delitos que podrían presentarse. Según Dillon (2005), tampoco uniendo las definiciones de la CNUMAR con la propuesta por el International Maritime Bureau podrían encuadrarse situaciones como la extorsión en puertos oficiales o el terrorismo marítimo, lo cual supone más que una cuestión de simple semántica. 


\section{A. Definición de piratería de la CNUMAR}

La CNUMAR de 1982, también conocida como la Convención de los Océanos (Zou, 2002) se puede considerar históricamente uno de los tratados más importantes en materia de derecho internacional, y por tanto obligatorio en esta materia (López y Fernández, 2009); sin embargo, en torno a la piratería recoge prácticamente el mismo articulado contenido en el Convenio de Ginebra de 1958.

El mantenimiento del tema de la piratería en los mismos términos en que se encontraba desarrollado en el Convenio de Ginebra, hace pensar que este no figuraba en la agenda de discusiones de la Convención, que empezaron desde el año 1967 motivadas por la explotación del lecho y fondos marinos, así como por la extensión del mar territorial en actos unilaterales de algunos Estados y que requerían de una regulación específica para evitar que se pudieran presentar conflictos internacionales al respecto (Zou, 2009; Gómez Robledo, 1999).

Tal circunstancia se acentúa debido a otros aspectos tratados dentro de la Convención, tales como la inclusión de nuevas zonas jurisdiccionales que merecen ser objeto de estudio a la luz del delito de piratería, y que obligan a realizar una interpretación para observar si estos facilitan la realización de tal conducta.

Mantener la redacción del Convenio de Ginebra de 1958 en lo referente a la piratería ha sido objeto de abundante crítica de la doctrina. Como se apuntó anteriormente, este delito ha mostrado una constante evolución, con lo cual acoger la definición del año 1958 significa obviar aspectos de su resurgimiento durante los últimos años, máxime cuando esta provenía de un proyecto que se le encargó a la Universidad de Harvard y que fue elaborado en el año 1932 (Barrios, 2005).

Por encima de toda crítica, el principal avance que puede apreciarse en este Convenio es el referente a la declaración de la jurisdicción universal, por cuanto permite una más eficaz lucha contra la piratería y contra cualquier conducta que pueda realizarse en altamar, pero que como más adelante se verá ha tenido sus propias dificultades, especialmente porque dicha jurisdicción universal tiene una aplicación directamente proporcional al interés que tengan los Estados en el ejercicio de las libertades propias de la altamar (Gaviria Liévano, 1993, p. 80). Así, sin ninguna variación respecto a la Convención de 1958, el artículo 101 de la cNumar establece que:

Constituye piratería cualquiera de los actos siguientes:

a) Todo acto ilegal de violencia o de detención o todo acto de depredación cometidos con un propósito personal por la tripulación o los pasajeros de un buque privado o de una aeronave privada y dirigidos:

i. Contra un buque o una aeronave en la altamar o contra, personas o bienes a bordo de ellos;

ii. Contra un buque o una aeronave, personas o bienes que se encuentren en un lugar 
no sometido a la jurisdicción de ningún Estado;

b) todo acto de participación voluntaria en la utilización de un buque o de una aeronave, cuando el que lo realice tenga conocimiento de hechos que den a dicho buque o aeronave el carácter de buque o aeronave pirata;

c) todo acto que tenga por objeto incitar a los definidos en el apartado a) o en el apartado b) o facilitarlos intencionalmente.

De acuerdo con lo transcrito podría interpretarse entonces la piratería como un robo armado que ocurre con el uso de violencia o amenaza, en un área que se encuentra fuera de la jurisdicción y control de cualquier Estado. Esta definición puede entenderse como bastante restringida e impráctica para abordar la situación actual (Sobrino, 2009), inclusive ambigua en la utilización de ciertos términos (Birnie, 1987). Por tal razón, para un mejor estudio de esta definición se separarán los puntos que más han sido objeto de críticas, los que concentran sus mayores falencias o discusión de acuerdo con la doctrina, y que por tanto mayor necesidad presentan de ser revisados.

\section{Limitación a los actos ocurridos} en alta mar

En primer lugar se restringe el delito de piratería solo a los actos ocurridos en altamar, fuera de la jurisdicción de cualquier Estado. Es válido anotar que la mayor parte de la superficie oceánica en el mundo se encuentra fuera de la jurisdicción de ningún Estado y esta es la causa prin- cipal por la cual se llama al concurso de todos los Estados por igual para combatir este delito. Por lo tanto no es casualidad que los artículos relativos a la piratería se encuentren ubicados en la parte VII de la convención dedicada a la alta mar.

Empero, con dicha orientación quedan excluidos los actos ocurridos en el mar territorial de los Estados, es decir los acontecidos mientras que la nave se encuentra navegando de camino a puerto, atracada o fondeada, los cuales teniendo en cuenta las estadísticas de la omı representan la mayoría de los casos. Por ejemplo, en el año 2003 , solo el $27 \%$ del total de los ataques reportados tuvo lugar en altamar (Dillon, 2005).

De manera más específica se pueden enunciar los casos de piratería en territorio asiático, compuesto por gran cantidad de archipiélagos; el caso de Filipinas; los ataques ocurridos en los distintos estrechos, como en el estrecho de Malaca, que quedan fuera del marco legal internacional. En estas áreas, cualquier Estado que pueda estar interesado en combatir abiertamente la piratería se encontraría con grandes dificultades para la persecución en caliente, además de las obstáculos geográficos (Barrios, 2005).

Estas situaciones deben entonces ser asumidas de conformidad con la ley del Estado donde se comete el delito, de tal manera que solo serán considerados como piratería si así se encuentran regulados por su ley penal (Hong y K.Y., 2010 , p. 52). Un escenario que se podría presentar, sería que en el país captor no exista una ley penal que tipifique como tal el delito de pi- 
ratería, con lo cual la comisión de la conducta punible quedaría impune, o simplemente dicho Estado podría optar por no iniciar la persecución (Kraska, 2009).

Desde otro punto de vista, se puede concluir que dicha definición está diseñada pensando en no afectar la soberanía de los Estados, y no realmente en responder a un contexto que ha venido agravándose durante los últimos años. Es una postura poco oportuna anteponer intereses económicos y políticos marcados por el egoísmo soberano de los dirigentes, a un problema puntual como lo es el delito de piratería marítima. Muy seguramente para las víctimas no tiene incidencia alguna el hecho que el delito haya sido cometido en el mar territorial o alta mar, sino el deseo de que este sea atacado frontalmente (Hastings, 2009).

El resultado de la piratería es el mismo sin importar dónde se cometa, por esta razón no debería existir diferencia en razón del lugar. Consideramos que podría llegar a pensarse incluso en la aplicación de agravantes o atenuantes para la determinación de la sanción imponible, pero no en una diferenciación como la aplicada en la definición, por tal razón no se entiende del todo la aplicación del principio fórum delictum comisi ya que la esencia de la piratería es la mar, sin distingo de que se trate de mar territorial (Martínez, 2009).

\section{Necesidad de un segundo buque}

De acuerdo con la definición, para perfeccionarse el delito debe realizarse por un buque contra otro. Es requisito sine qua non la presencia de una segunda embarcación, quedando inmediatamente por fuera de la definición los actos de amotinamiento (Johnson y Pladdet, 2003). No puede tratarse de los pasajeros contra la tripulación, ni de la tripulación contra los pasajeros, ni siquiera en el caso que un acto incluya todos los elementos previstos por el artículo 101, si falta la segunda embarcación ya no será considerado piratería (Treves, 2009).

Es posible entender que un simple acto de violencia en la embarcación no puede calificarse inmediatamente como piratería. Mas existen casos que van más allá de episodios aislados, que pueden comprometer la seguridad de la embarcación, y que por sus condiciones no pueden ser configuradas como un amotinamiento. Por esta razón ciertos Estados en su propia normativa sobre piratería incluyen la posibilidad de que esta sea cometida por una sola embarcación, apartándose de la definición prevista en la cNuMAR. Según Ruiz, Arranz y Zabaleta (1993), de acuerdo con las reglas de interpretación de la Marine Insurance Act de 1906, el término pirata comprende a los pasajeros que se sublevan.

Tal definición no permite siquiera la posibilidad de una interpretación amplia, en el sentido de admitir que el delito de piratería pueda perfeccionarse con la presencia de un solo barco (Jesus, 2003). Acogiéndonos al tenor literal de la definición, en el caso de apresamiento de la tripulación por los pasajeros o viceversa, no estarían legitimados los buques de guerra extranjeros para intervenir, toda vez que dicha intervención solo será válida en actos que sean subsumibles 
dentro de lo previsto en el citado artículo 101. Esta realidad deja a las víctimas a la deriva y sin posibilidad de respuesta alguna, en un medio en que difícilmente el Estado de la bandera de la embarcación podrá responder.

Por lo tanto, en este tipo de escenarios, solo habrá respuesta si la embarcación se encuentra en el mar territorial del pabellón que lleva la nave, lo cual según Halberstam (1988) ha sido el criterio mantenido en este tema: que los actos ocurridos dentro de la embarcación sean atendidos por el Estado de la bandera. Son más las desventajas, que las ventajas que puede ofrecer una postura como la propuesta, teniendo en cuenta que existen muchas embarcaciones que enarbolan banderas de conveniencia, inscritas en Estados que no tienen los medios suficientes para responder de una forma efectiva en este tipo de casos.

Por último anotar, que según Garmon (2002) se han presentado casos de amotinamientos y conversión de la embarcación que constituyen una excepción a lo previsto por esta norma, pero sobre estos no se ha establecido cuál o cuáles han sido los criterios observados para determinar en qué circunstancias se pueden presentar dichas excepciones (p. 261). Este tipo de excepciones una vez más muestra la debilidad de esta definición. Peor aún, muestra que los Estados ante tales dificultades están optando más por la aplicación de sus propias normas que por las de la Convención, ante la falta de respuesta internacional a un problema que como ya se dijo, necesita acciones puntuales y expeditas.

\section{La existencia de un fin privado}

De acuerdo con la definición de piratería de la CNUMAR, para perfeccionarse el delito, este debe realizarse con un fin privado. Existe una discusión respecto de la necesidad exclusiva de un fin privado, o si es posible que se realice también con un fin público, entendiéndose por fines públicos los políticos, religiosos, o cualquier actividad de tipo ideológico. Y por último, si es indistinto el hecho de que se trate de un fin público o privado, lo cual de acuerdo con Jesus (2003) en últimas debe ser considerada como una causa perdida.

Entre los partidarios de eliminar de la definición la anotación sobre que la piratería solo puede cometerse con un fin privado se encuentra Birnie (1987), quien anota que la piratería con fines políticos siempre ha existido, razón por la cual no tendría sentido esta distinción. No obstante, al realizar una lectura un poco más profunda de lo que este autor entiende por piratería política, se observa que presenta más la forma de terrorismo, puesto que posteriormente señala que dichos actos de piratería política generalmente no incluyen el robo.

Zou (2009) considera que debe ser irrelevante si se persiguen fines públicos o privados, puesto que es normal que tras el fin personal se esconda un interés político, como lo apunta Sobrino (2009) apelando al ejemplo del Corso. Por su parte, Barrios (2005) entiende que es importante que se admitan los fines políticos para que puedan ser juzgados como piratería 
los actos de grupos disidentes regionales contra ciertos gobiernos. Dos posturas que apoyan esta tesis pero en un plano más moderado son la de Martínez Alcañiz (2009) quien aboga por la eliminación del elemento subjetivo, anotando que solo debe valorarse el daño objetivamente y el dolo con el que se haya cometido; y Cervera Pery (1992), quien apunta que la interpretación del fin privado de la piratería de la cNUMAR debe tenerse en cuenta sin perjuicio del derecho que les asiste a los Estados de promulgar su propia normativa, con la orientación que consideren más oportuna.

A la defensa de que la piratería solo puede cometerse bajo un fin privado se encuentra Halberstam (1988), para quien el delito de piratería debe encerrar, en exclusiva, un fin privado. Rodríguez Núñez (1997) anota que “el pirata (...) actúa en beneficio propio”, al compararlo con el corsario, agregando que si bien este en la actualidad ya no existe, sí sirve como punto de partida para observar la diferencia de cuando el pirata actúa con un fin público, que es cuando lo hace con la licencia del corsario, a cuando lo hace por su propia cuenta exclusivamente buscando el fin privado, desconociendo autorización, ni autoridad gubernamental.

Una postura ecléctica es la que mantiene Jesus (2003), quien a su vez anota que si bien puede considerarse que la piratería debe cometerse con fines privados, la CNUMAR no contiene referencia en ninguna parte respecto de qué debe entenderse por fines privados; de esta forma debe ser el juez que conozca del caso el encargado de valorar, de acuerdo con los elementos que tenga a su disposición, si dicho acto se realizó efectivamente con un fin público o privado.

Por otro lado, Eadie (2004) considera que dentro de los fines privados bien podrían encuadrarse los motivos de índole política. A esta postura se opone Urbina (2009), para quien la definición, tal como se encuentra, excluye la posibilidad de que la motivación sea política, inclusive no hace referencia siquiera a un fin religioso o cultural, que actualmente parece confundirse con lo político. Aspecto que es de vital importancia toda vez que permite distinguir los actos de piratería de otras actividades ilegales, en especial del terrorismo (pp. 333 y 334).

Así las cosas, se observa que la doctrina defiende mayoritariamente, si bien con algunos matices, la tesis de que el fin de la piratería debe ser privado. Nos unimos a esta postura y señalamos que es más acertado pensar que la piratería solo debe ser entendida como un acto con un fin privado. Nos parece que es claro, que los intentos de entender que la piratería debe incluir fines de índole pública, política o ideológica, se han dado a partir de los actos terroristas que han ocurrido en los últimos años. Esta postura cobra mayor fuerza al observar lo anotado por Garmon (2002), en el sentido que los redactores Harvard, del proyecto de convención de 1932, tenían la intención exclusiva que la piratería se limitara a fines privados.

En este sentido compartimos la tesis de Johnson y Pladdet (2003), quienes opinan que de considerar piratería cualquier acto indistintamente de sus fines públicos o privados, llevaría 
a condenar asimismo como piratería cualquier protesta realizada por grupos ambientalistas 0 Greenpeace contra embarcaciones que realizan pescas de especies protegidas $u$ otras actividades ilegales que ponen en peligro el medio ambiente marino.

Por último, comentar uno de los casos más famosos en este tema, el Republic of Bolivia vs. Indemnity Mutual Marine Insurance Co. Ltd. (1909, 1BK, pp. 796 y ss.), en el cual el juez de conocimiento indicó que un pirata es una persona que saquea un buque en beneficio propio, no quien actúa por motivos políticos o con la intención de derrocar a un gobierno. Postura jurisprudencial a la que nos adherimos. ${ }^{13}$

\section{Otras críticas}

Además de las anteriormente anotadas, la definición de piratería contenida en la CNUMAR ha recibido otro tipo de críticas, que si bien no han sido tan discutidas, consideramos que dentro del presente estudio merecen ser analizadas.

Por una parte, que actualmente la situación planteada en el literal a) ii) del citado artículo 101 es imposible que en la práctica pueda ocurrir, puesto que las zonas de Terra Nullius, hoy en día prácticamente no se pueden encontrar (Jesus, 2003). De otra, que la parte anotada en el literal a) i), en el sentido que la piratería también

13 Sin embargo, este caso presenta una situación particular. Los hechos no tuvieron lugar en mar abierto, sino en un río entre Brasil y Bolivia, por lo cual se entiende que la póliza debía cubrir la piratería inclusive en aguas internas. podría realizarse respecto de aeronaves nos parece poco razonable (McDougal y Burke, 1987). Creemos que los casos de secuestro de aeronaves deberían tener más bien la consideración de terrorismo, situación distinta a la piratería, como más adelante se verá en este trabajo.

Se hace también una crítica ya no a la definición, sino a la cNUMAR como tal, que por no tratarse de un concepto único adoptado por todos los Estados, no recoge en su seno la realidad de la costumbre internacional. En sentido contrario, directamente relacionadas con el número de Estados que han ratificado dicha Convención, y con la definición misma de piratería, deben estar las acciones para combatirla.

Se critica la actitud pasiva en cuanto a la piratería, en el sentido de no crear un tribunal especial para perseguirla o juzgarla, desconociendo que el artículo 100 de la Convención permite la organización de acciones para su combate (Mo, 2002). Este vacío ha dificultado que se pueda llevar a las personas individualmente para que sean juzgadas por sus actos (kahn, 1996); por lo tanto, la creación de un tribunal de segunda instancia que conozca dichas situaciones sería fundamental para juzgar los casos de piratería marítima (Abi-Saab, 2003), competencia que podría darse a la Corte Internacional de Justicia (Sierra, 2010), incluso en aquellos Estados que no hayan desarrollado mecanismos o normas internas a tono con la norma internacional para combatirla, en virtud del artículo 100 de la Convención que obliga a todos los Estados a cooperar con la represión de la piratería, o para Ilamar la atención de aquellos Estados que con- 
tando con los medios suficientes para colaborar, lo hacen solo de manera parcial.

La forma en que la cNUMAR define el tema de la piratería puede considerarse, entonces, la causa de la dicotomía existente entre las diferentes normativas nacionales y la Convención internacional. La definición aborda el problema a nivel de Estados y no de individuos. Como se ha anotado hasta aquí, la definición es demasiado estricta en el contexto espacial al limitarla solo a alta mar quedando por fuera de su alcance un gran número de casos; a contrario sensu, parece ser demasiado amplia, al dejar por definir la postura que los Estados en general deberían asumir en cuanto al trato interno de los piratas, como en lo referente a las penas aplicables y a los bienes que les sean hallados, respecto del procedimiento para su posterior confiscación (Kraska y Wilson, 2009).

El reconocimiento internacional de una conducta como digna de reproche y sanción no debe limitarse a un simple enunciado, debe ir acompañado de una propuesta adicional que permita realizar acciones concretas orientadas a ponerle freno (Kraska y Wilson, 2009). Este punto no es posible encontrarlo en la CNUMAR.

Quizás por estas razones es común ver que en algunos Estados, en materia de piratería, prima la aplicación de sus propias normas internas frente a los lineamientos de la cNUMAR (Eadie, 2004). Sin embargo, esta opción del desarrollo de normativas nacionales paralelas a lo dicho en la Convención también presenta sus dificultades aplicativas, incluyendo el hecho latente de las diferencias que se pueden presentar al tratar de armonizar las normativas de cada Estado (Birnie, 1987).

Otra situación que de presentarse no estaría regulada por la CNUMAR, es la de la captura de piratas por embarcaciones no autorizadas. Según el artículo 105 de la Convención, todos los Estados están autorizados para proceder a la captura de piratas cuando se hallen en alta mar. Posteriormente el artículo 107 de la Convención determina que solo podrán realizar tales capturas las naves militares o especialmente autorizadas para ello, al servicio de un gobierno.

Debido al aumento del número de ataques, las navieras, e incluso algunos gobiernos han implementado el uso de seguridad privada y armamento a bordo para repeler tales ataques, ${ }^{14}$ aspecto este que es aceptado por el mismo Consejo de Seguridad de las Naciones Unidas. ${ }^{15}$

En un supuesto enfrentamiento, si una embarcación lograra someter y capturar a los piratas a los que se enfrenta, no podría considerarse una captura legal, conforme a la Convención. La CNUMAR no establece nada a este respecto.

14 El diario El País, publicó el 8 de abril de 2010 una noticia titulada "Defensa envía 19 ametralladoras más para los atuneros", en la cual hacen referencia al tipo de armamento que el Ministerio de Defensa español actualmente está proporcionando a los atuneros españoles que navegan por aguas del Índico para repeler los ataques piratas. Disponible en: http://www.elpais.com/articulo/espana/Defensa/envia/ ametralladoras/atuneros/elpepunac/20100408elpepinac_20/Tes; estamos de acuerdo con Sierra Noguero en el sentido de que armar a la población civil no es la mejor opción, por el riesgo que esto supone, además de los problemas que puede acarrear para la embarcación dependiendo de la normativa de los Estados por los que el buque navegue $(2010$, p. 60$)$.

15 Véase Resolución 2077 de 2012 del Consejo de Seguridad de las Naciones Unidas. 
Es precisamente esta ausencia de reglas la que ofrece un clima especial para el desarrollo de las actividades ilegales (Sanderson, 2004). Se trata, pues, de una definición parcial que no aborda la totalidad de situaciones. Consideramos que este tipo de críticas permiten concluir que la construcción de dicha definición se funda en elementos tradicionales y estáticos, con lo cual no es posible introducir las situaciones que actualmente se vienen produciendo (Urbina, 2009).

\section{CONCLUSIONES}

La piratería marítima es un problema vigente. Los intentos para ponerle freno si bien han sido útiles, no han resultado suficientes. Por esta razón, lo que ha ocurrido es que se han venido trasladando los puntos en los que geográficamente se concentra la problemática, sin embargo las estadísticas de pérdidas económicas y humanas se han mantenido constantes. Latinoamérica y el Caribe no presentan mayores casos de este delito, en parte por los patrullajes constantes de la Armada de Guerra de los Estados Unidos en las distintas fuerzas operacionales que la componen y del Departamento de Estado Americano (DEA), en razón del control del narcotráfico. Empero, lo anterior no supone que América esté exenta de que dicha problemática se incremente, debido a las turbulencias e inestabilidades sociales y políticas que presentan sus países.

Todo el mundo en la actualidad es tocado directa o indirectamente por esta situación. No obs- tante, en los casos en los que la afectación es indirecta, la voluntad política para buscar una solución al problema es menor o inexistente, lo que dificulta la adopción de decisiones de fondo. Se requiere entonces tener presente lo previsto en la Convención del Derecho del Mar: el combate contra la piratería compete a todos los Estados por igual, y no exclusivamente a aqueIlos Estados que se ven mayormente afectados. Dicha manifestación debería también servir como mecanismo coercitivo para exigir a todos los Estados igual interés en la búsqueda de una salida, bien a través de una reforma a algunas de las previsiones de la Convención, bien con la destinación de recursos para incrementar la vigilancia y los patrullajes en alta mar y en los límites del mar territorial de los diferentes Estados.

La falta de voluntad política es quizás uno de los aspectos que mayormente ha dificultado el establecimiento de una solución práctica frente al delito de piratería. Cada vez que se discuten aspectos territoriales o asociados a la soberanía de los Estados, los gobernantes son renuentes a aceptar cualquier actuación que pueda considerarse una intromisión en sus asuntos internos o en su poder soberano. Por lo tanto, es preciso cambiar este paradigma en aras de responder más a una necesidad global que a un capricho político, y eliminar de las discusiones al respecto intereses distintos al de lograr claridad en los términos que se apliquen para afrontar todo lo relativo a la piratería marítima.

La solución tampoco debe ser vista exclusivamente en la mar, o simplemente restringida a la adopción de medidas como una mayor vigilan- 
cia o la autorización para que los buques mercantes puedan portar armamento para repeler Ios ataques. El problema empieza en tierra con la falta de oportunidades laborales y de educación, y es allí donde precisamente se deben fortalecer las políticas, para que las personas que se dedican a cometer este delito no lo vean como la única opción posible de supervivencia o sustento. La destinación de recursos para capacitación e industrialización de los pescadores artesanales en zonas pesqueras, o la suscripción de convenios de compra pueden ser una solución; al mismo tiempo, el compromiso de acabar con la pesca de arrastre y de propender por el mantenimiento de las especies marinas para garantizar la reproducción, serían políticas sanas que generarían bienestar y paz, especialmente en las zonas más pobres, que son, en últimas, donde sus habitantes son más propensos a incurrir en la piratería marítima.

Más allá de todo lo anotado, se requiere la adopción de un nuevo documento internacional que tenga en cuenta los distintos aspectos que actualmente apareja el delito de piratería, y que sea producto de una convención en la que se acuerde: 1) una definición que permita unificar las diferencias existentes, 2) tratar frontalmente el problema, 3) despejar cualquier duda sobre interpretaciones sombrías que puedan ser utilizadas para sacar provecho de la situación, y 4) incluir políticas de educación, trabajo y reinserción. Un acuerdo internacional de este orden hará más eficientes las acciones en la mar, servirá de advertencia para los piratas, contribuirá a hacer más atractivas las condiciones en tierra y ayudará a que deje de verse el delito de piratería como una alternativa rentable.

\section{Referencias}

Abi-Saab, G. (2003). The Proper Role of Universal Jurisdiction. Journal of International Criminal Justice, I(3), 596-602.

Bantekas, I. (2005). Head of State Immunity in the Light of Multiple Legal Regimes and NonSelf-Contained System Theories: Theoretical Analysis of ICC Third Party Jurisdiction Against the Background of the 2003 Iraq War. Journal of Conflict \& Security Law, X(1), 21-42.

Barrios, E. (2005). Casting a Wider Net: Addressing the Maritime Piracy Problem in Southeast Asia. Boston College International Comparative Law Review, XXVIII(1), 149-164.

Bichou, K. (2008). Security and Risk-Based Models in Shipping and Ports: Review and Critical Analysis. London: Centre for Transport Studies. University of London - Imperial College.

Birnie, P. (1987). Piracy: Past, Present and Future. Marine Policy, XI(3), 163-183.

CarvajaL, P. I. (2007). Naufragio, piratería y "sodales" marítimos. Revista de Estudios HistóricoJurídicos, XIX, 233-243.

Cervera Pery, J. (1992). El derecho del mar. Evolución, contenido, perspectivas (De las Bulas Papales al Convenio de Jamaica). Madrid: Editorial Naval. 
Chalk, P. (2008). The Maritime Dimension of International Security. Terrorism, Piracy and Challenges for the United States. Obtenido de Rand Corporation: http://www.rand.org/pubs/monographs/MG697/

Corrales Elizondo, A. (2004). Soluciones jurídicas actuales en relación a la piratería y otros delitos graves en la mar. Obtenido de Fundación Asesmar: http://www.asesmar.org/conferencias/temas/politicamaritimayderechomaritimo. htm

Dillon, D. (2005). Maritime Piracy: Defining the Problem. SAIS Review of International Affairs, XXV(1), 155-165.

Eadie, E. (Mayo-Junio de 2004). Relevance of International Criminal Law to Piracy in Asian Waters. Maritime Studies, (136), 21-33.

Fairman, Ch. (1935). A Note on Re Piracy Jure Gentium. The American Journal of International Law, XXIX(3), 508-512.

Forsyth, C., Gisclair, K. y Forsyth, Y. (2009). Waterborne Crime: Examining Contemporary Piracy. Deviant Behavior, XXX(8), 669-679.

Garmon, T. (2002). International Law of the sea: Reconciling the Law of Piracy and Terrorism in the Wake of September 11th. Tulane Maritime Law Journal, XXVII(1), 257-275.

Gaviria Liévano, E. (1993). Derecho Internacional Público (Cuarta ed.). Bogotá: Editorial Temis.
Gómez Robledo, A. (1999). La Convención de Montego Bay. Génesis de la misma y el unilateralismo como técnica jurídica. En Temas Selectos de Derecho Internacional (Tercera ed., págs. 317-333). México, D. F.: Universidad Nacional Autónoma de México.

Halberstam, M. (1988). Terrorism on the high seas: The Achille Lauro, Piracy and the ımo Convention on Maritime Safety. The American Journal of International Law, LXXXII(2), 269-310.

Hastings, J. (2009). Geographies of state failure and sophistication in maritime piracy hijackings. Political Geography, XXVIII(4), 213-223.

Hong, N. y K.Y., A. (2010). The international legal instruments in addressing piracy and maritime terrorism: A critical review. Research in Transportation Economics, XXVII(1), 51-60.

House of Commons. Transport Committee. (Junio 28 de 2006). Piracy. Eighth Report of Session 2005-2006. Obtenido de publications.parliament: http://www.publications.parliament.uk/ pa/cm200506/cmselect/cmtran/1026/1026. pdf

Jesus, J. L. (2003). Protection of Foreign Ships against Piracy and Terrorism at Sea: Legal Aspects. The International Journal of Marine and Coastal Law, XVIII(3), 363-400.

Johnson, D. y Pladdet, E. (2003). An overview of current concerns in piracy studies and new directions for research. Obtenido de Centre for Maritime MARE Research: http://www.marecen- 
tre.nl/people_and_the_sea_2/documents/piracy.pdf

Kahn, L. (1996). Pirates, Rovers, and Thieves: New Problems with and Old Enemy. Tulane Maritime Law Journal, XX(2), 293-329.

Kontorovich, E. (2004). The Piracy Analogy: Modern Universal Jurisdiction's Hollow Foundation. Harvard International Law Journal, XLV(1), 183237.

Kraska, J. (2009). Coalition Strategy and the Pirates of the Gulf of Aden and the Red Sea. Comparative Strategy, XXVIII(3), 197-216.

Kraska, J. y Wilson, B. (2009). Maritime Piracy in East Africa. Journal of International Affairs, LXII(2), 55-68.

López Quiroga, J. y Fernández-Quirós, T. (2009). La piratería marítima en el Derecho Internacional. Actualidad Jurídica Uría \& Menéndez, (22), 102-105.

Martínez Alcañiz, A. (Enero-Febrero, 2009). Cuestiones jurídicas sobre piratería en la mar. Revista General de Marina, CCLVI(3), 229-250.

McDougal, M. y Burke, W. (1987). The public order of the oceans: a contemporary international law of the sea. New Haven: New Haven Press.

Mo, J. (2002). Options to Combat Maritime Piracy in Southeast Asia. Ocean Development \& International Law, 33, Issue 3-4, 343-358.
Morrison, S. (1932). A collection of piracy laws of various countries. The American Journal of International Law, XXVI(1), 887-1013.

Murphy, M. (July, 2007). Chapter Three: Assessing the Threat. En Contemporary Piracy and Maritime Terrorism: The Threat to International Security (págs. 73-88). Abingdon: Routledge.

Ndumbe, J. y Moki, S. (2009). Africa: The Piracy Hot Spot and Its Implications for Global Security. Mediterranean Quarterly, XX(3), 95-121.

Passman, M. (2009). Interpreting Sea piracy Clauses in Marine Insurance Contracts. Journal of Maritime Law \& Commerce, XL(1), 59-88.

Risso, P. (2001). Cross-Cultural Perceptions of Piracy: Maritime Violence in the Western Indian Ocean and Persian Gulf Region during a Long Eighteenth Century. Journal of World History, XII(2), 293-319.

Rodríguez Núñez, A. (1997). El delito de piratería. Anuario de Derecho Penal y Ciencias Penales, I(50), 211-262.

Ruiz Soroa, J., Arranz de Diego, Á. y Zabaleta Sarasua, S. (1993). Manual de Derecho del Seguro Marítimo. País Vasco: Gobierno Vasco, Departamento de Transportes y Obras Públicas, Dirección de Puertos y Asuntos Marítimos.

Sakhuja, V. (2000). Maritime Order and Piracy. Strategic Analysis, XXIV(5), 923-938. 
Sanderson, T. (2004). Transnational Terror and Organized Crime: Blurring the Lines. SAIS Review of International Affairs, XXIV(1), 49-61.

Sierra Noguero, E. (2010). Régimen jurídico de la prevención y enjuiciamiento de la piratería marítima. Revista de Derecho del Transporte, (4), 39-66.

Sobrino, J. (2009). La piratería marítima: un crimen internacional y un galimatías nacional. Recuperado el 26 de agosto de 2014, de reei.org: http://www.reei.org/index.php/revista/num17/ agora/pirateria-maritima-crimen-internacionalgalimatias-nacional

Treves, T. (2009). Piracy, Law of the Sea, and Use of Force: Developments off the Coast of Somalia. The European Journal of International Law, XX(2), 399-414.

Urbina, J. (2009). La cooperación internacional en la prevención y control de los actos de pira- tería en el actual Derecho del Mar. En J. Pueyo Losa y J. Urbina (Coords.), La cooperación internacional en la ordenación de los mares y océanos (págs. 321-362). Madrid: lustel.

Warner, L. (2010). Pieces of Eight. An Appraisal of U.S. Counterpiracy Options in the Horn of Africa. Naval War College Review, LXIII(2), 61-87.

White, E. (1989). The Marshall Court and International Law: The Piracy Cases. The American Journal of International Law, LXXXIII(4), 727735.

Zou, K. (2002). Disrupting or Maintaining the Marine Legal Order in East Asia? Chinese Journal of International Law, I(2), 449-498.

Zou, K. (2009). New Developments in the International Law of Piracy. Chinese Journal of International Law, VIII(2), 323-345. 